\title{
The Impact of Core Firing on EOR of Low Salinity-Surfactant Flooding
}

\author{
Anthony Kerunwa \\ Federal university of Technology, Owerri, Nigeria \\ Email: anthonykerunwa@rocketmail.com
}

How to cite this paper: Kerunwa, A. (2020) The Impact of Core Firing on EOR of Low Salinity-Surfactant Flooding. Open Journal of Yangtze Gas and Oil, 5, 103-116. https://doi.org/10.4236/ojogas.2020.53009

Received: April 9, 2020

Accepted: May 19, 2020

Published: May 22, 2020

Copyright $\odot 2020$ by author(s) and Scientific Research Publishing Inc. This work is licensed under the Creative Commons Attribution International License (CC BY 4.0).

http://creativecommons.org/licenses/by/4.0/ (c) (i) Open Access

\begin{abstract}
The combination of injection of lower saline brine and surfactant will increase recovery in sandstone rocks than either when any of the techniques is singly applied. In this work, core IFT test, $\mathrm{pH}$ test, flooding experiments and measurement of dispersion were performed on four core samples which were grouped into two: group A which were not fired and group B which were fired at a temperature of $500^{\circ} \mathrm{C}$ for 24 hours. Two low saline brines were prepared: LS1 which was derived by the dilution of seawater four times and LS2 which was derived by ten times diluting the seawater. The surfactant used was ethoxylated alcohol surfactant. Coreflood experiments were then performed on the rock samples starting with the injection of low saline followed by low saline brine combined with surfactant (LSS). Results from the experiments show that with the injection of LS1 brine and LSS1 higher increment in recoveries were obtained for group B than for group A cores. The same trend was also noticed with the injection of LS2 and LSS2. From the results, LS1 gave higher increment in oil recovery than LS2. Also LSS1 gave higher recoveries when compared with LSS2. In all the cases tested, core samples which were fired gave higher recoveries even though they had low permeabilities of 993 md for sample 3 and 1017 md for sample 4 than those which were not fired with higher permeabilities of $1050 \mathrm{md}$ and $1055 \mathrm{md}$ for samples 1 and 2 respectively. This was attributed to the alteration of wettability as well as that of permeability caused by sample firing. The dispersion profiles of the rock samples show that all samples are homogeneous.
\end{abstract}

\section{Keywords}

Interfacial Tension, Wettability, Oil-Water Interaction, Surfactant, Low Salinity Brine

\section{Introduction}

EOR requires an indebt understanding of how oil and other components that are 
present in the petroleum reservoir interact. Petroleum reservoir contains different fluids mixed together as well as different minerals that compromise every geological system which are formed several thousands of years ago. These fluids comprise formation brine and crude oil and, these interact with the surfaces of reservoir rocks. Oil/water (formation brine)/rock system interaction is complex and this interaction affects the outcomes/results of EOR. Oil/water (formation brine)/rock interactions demand thorough investigation to ensure that EOR implementation strategies are successful and this interaction together with interfacial tension control capillary forces. Capillary forces themselves are physical forces which ensure that oil is entrapped as residual oil at the end of every secondary recovery operation. The main approach for EOR is therefore to manipulate the injected fluids in a manner that will minimize the interfacial tension existing between the fluids or cause a change in porous media wettability. Wettability alteration can greatly affect the location of fluids, mostly the flow of fluid, the distribution of residual oil in the rock and the recovery of oil [1] [2], thereby affecting relative permeability [3] as well as capillary pressure [4]. A movement in the residual oil needs an amount of energy that is in the form of viscous force usually initiated by the pressure difference existing between the reservoir and the wellbore. The viscous force is in turn affected by physical phenomena like contact angle, capillary pressure, capillary number and interfacial tension [2] [5]. Oil recovery from all reservoirs subject to increase in water/oil contact or waterflooding is governed by the phenomena of spontaneous imbibitions [6] [7]. Waterflooding remains most common and generally employed oil recovery approach practiced by the petroleum industry since 1930s. By convention, waterflooding was regarded as a physical process for the recovery of oil that serves two major functions namely: 1) to maintain the pressure of the reservoir and 2) to enforce the displacement of oil from the pore space of the reservoir to the producing wells by viscous forces. Nevertheless, the saturation of residual oil left behind after waterflooding is always on the high side [8] [9]. The research work carried out by Surface Chemistry and Petrophysics of the Wyoming University Research Group has revealed that the salinity of injection-water plays a significant role in the performance of oil recovery performance through waterflooding process [10] [11] [12] [13]. Reiter in his work, demonstrated that alteration in the composition of the brine or a reduction in the brine salinity lower than that of initial formation water can significantly lead to extra recovery of oil for the Berea core used for the experiment [14] [15], since the saturation of residual oil could be greatly reduced by low salinity [16]. The increment in oil recovery that occurs from sandstone when low salinity water is used is explained by several mechanisms such as: ion exchange in multicomponent system [17], mineral dissolution [18], double-layer expansion [19], fines migration [10], reduction in interfacial tension [20] and desorption of organic matter from surface of clay [21]. The clay presence in the reservoir [18] [19] [20] [21] [22] and the injected water chemical composition [20] [22] [21] [22] [23] are other factors affecting additional recovery of oil [20]. However, no consensus exists on the purely do- 
minant mechanism for enhancing the recovery of oil in sandstone reservoir. This is because many simultaneous processes greatly contribute to the entire process [16]. The chemical heterogeneity of the Reservoir may also play a part. Field scale and experimental projects show that incremental oil production by the flooding of brine with low salinity greatly varies case-by-case in carbonates as well as sandstones [24]. Minerals contained in natural porous rocks are unevenly distributed in random spatial patterns, while some are uniform in their distribution and others are clustered [25]. Physical heterogeneity on one hand, changes flow fields together with the spatial ions distribution [26] while Chemical heterogeneity on another hand greatly changes the rate of dissolution [27] and desorption/ adsorption [28]. A Combination of chemical and physical heterogeneity can largely affect wettability alteration plus water-rock interaction [4]. Since the mechanism for oil recovery in low saline brine injection is not completely understood, wettability alteration has been observed in various experiments. Hence, it is assumed that wettability alteration remains the basic mechanism for low salinity flooding while the factor controlling wettability alteration is double-layer expansion [29].

Surfactants are known to be surface-active agents. Addition of surfactants to the water that is injected causes a reduction in the oil/water IFT and/or the wettability of the formation altered [29] [30]. Injection of surfactant has been identified as a well-known technique for improving oil recovery. Surfactant injection increases the recovery of oil by reduction of the IFT of oil-water system, and thereby preventing oil from being capillary trapped as well as remobilises any trapped oil [31]. High recoveries from surfactant flooding are anticipated to flow at low IFT that is, at capillary number whose value is high, then with low surfactant retention [32]. Surfactants that will yield low IFT at salinities that are low are within reach and they are not expensive compared to those that are efficient at high salinities. In addition, when the salinity increases, the surfactant retention also increases [33]. The positive results obtained from low salinity waterflooding coupled with the possibility of obtaining more recoveries from the process by the addition of surfactant, Alagic and Skauge [34] carried out a hybrid EOR process that combines low salinity brine effect with surfactant injection. The purpose was to create a more efficient process for oil recovery that combines the destabilization of oil layers during low saline brine injection with low IFT environment that hinders re-trapping of mobilised oil. Alameri et al. [35] in their work, they applied low-salinity water together with surfactants in carbonate reservoirs with oil-wet system to circumvent the challenges brought about by high salinity and thereby improve recovery in the reservoirs. From the literature review conducted, several researchers who studied EOR through low saline brine, surfactant and a combination of the two did not investigate the effect of core firing. In this work, investigation on the impact of core firing on low salinity-surfactant flooding with Niger Delta sandstone rocks was carried out. To have indebt knowledge of fluid flow in the reservoir core sample, dispersion measurements were also carried out at Sor as well as at water saturation of $100 \%$. 
Profiles of dispersion for all the rock samples were carried out after cleaning with toluene and methanol.

\section{Materials and Method}

\subsection{Crude Oil}

Crude oil BUK 1 of $56^{\circ} \mathrm{API}$ at $25^{\circ} \mathrm{C}$ from Niger Delta BUK reservoir with viscosity of 6.1413 measured with the aid of cannon viscosimeter was utilized for the experiments. The crude oil was filtered with $1 \mathrm{~mm}$ filter paper and then vacuumed before it was used.

\subsection{Sea Water}

The synthetic sea water composition which is a representative of the brine for BUK Reservoir depicted in Table 1, with low-salinity brine also depicted in Table 2 used for coreflooding, contact angle measurement of the oil-brine-rock system and brine-oil interfacial tension determination. The sea water density and viscosity were measured as $1.0317 \mathrm{~g} / \mathrm{ml}$ and $0.934 \mathrm{cp}$ respectively. The sea water has a total dissolved solid of 36,340 parts per million as also depicted in Table 1.

\subsection{Surfactant}

A non-ionic surfactant is used for the experiment. It is an ethoxylated alcohol surfactant consisting of about 8 moles of ethylene oxide in every mole of alcohol. The surfactant utilized was in compatibility with reservoir conditions as indicated by IFT studies.

\subsection{IFT Test}

IFT existing between two immiscible fluids, that is, oil and bulk fluid was measured with the Fisher Scientific Tensiometer Model 20. The procedure as stipulated

Table 1. Composition of Synthetic seawater (SW).

\begin{tabular}{rr}
\hline Salt & Composition \\
\hline $\mathrm{NaCl}$ & 29.69 \\
$\mathrm{KCl}$ & 0.89 \\
$\mathrm{MgCl}_{2}$ & 5.76 \\
$\mathrm{TDS}$ & 36.34
\end{tabular}

Table 2. Low-salinity brines (LS1 and LS2).

\begin{tabular}{ccccr}
\hline & & & \multicolumn{2}{c}{ Compound in 1000 ppm } \\
\cline { 3 - 5 } & $\mathrm{NaCl}$ & $\mathrm{KCl}$ & $\mathrm{MgCl}_{2}$ & TDS \\
\hline LS1 & 7.423 & 0.223 & 1.440 & 9.086 \\
LS2 & 2.969 & 0.089 & 0.576 & 3.634 \\
\hline
\end{tabular}

${ }^{*}$ ppm $=$ parts per million 
in the Fisher Tensiometer Model 20 manual was utilized in this study. The test sample was prepared in the ratio of 1:1 by weight of oil /aqueous phase, then equilibrated for twelve days before testing was performed. The sufficient time period provided allowed phase separation to be clear and stable. The measurement of IFT was carried out between the excess oil phase and the adjacent lower microemulsion phase which was equilibrated since the formulated surfactant formed a two-phase system (Winsor I system) at the applied salt concentration as depicted in Table 2.

\section{5. pH Test}

The $\mathrm{pH}$ measurement was carried out with aid of an electronic device called $\mathrm{pH}$ meter and all measurements were made after calibration. The measuring probe of the $\mathrm{pH}$ meter was placed in the aqueous solution and after allowing the needle to stabilize, the reading was taken. The probe was washed and the procedure repeated.

\subsection{Displacement Experiment}

Four core samples of diameter 3.81 and length $6.35 \mathrm{~cm}$ were utilized for the experiment. The cores samples were prepared and then cleaned with methanol and toluene in soxhlet extraction chamber. The rock samples were grouped into two-Group A (samples 1 and 2) and Group B (samples 3 and 4). Samples of group A were not fired while those of group B were fired in an oven at a temperature of $500^{\circ} \mathrm{C}$ for 24 hours to reduce the activity of clay minerals. Samples were thereafter oven dried at a lowered temperature of $85^{\circ} \mathrm{C}$ for 12 hours to preserve the content of the minerals of Group A core samples. The dimensions are representatives of the conventional laboratory scale. The cores samples were dried at $85^{\circ} \mathrm{C}$ to constant weight, with the dried rock samples loaded in a saturator and then connected to an Enerpac Pump. Introduction of brine into the saturator under vacuum was done through the Enerpac Pump. The whole system was pressurized to 2500 psi for 48 hours to achieve $100 \%$ sample saturation. At the expiration 48 hours, pressure was released and core samples removed from the saturator and then weighed. The saturated samples were then mounted in hassler core holders of Figure 1 at a confining pressure of 1000 psi with formation water (FW) injected at $2 \mathrm{cc} / \mathrm{sec}$ flow rate. This was done to ensure that the rock sample is still at $100 \%$ saturation and also to ensure that bubbles of air were not trapped in the pores. At this point the relperm of the core to brine was determined as depicted in Table 3 and also shown in Table 3 are the rock samples' physical properties. Thereafter crude oil sample BUK 1 with properties shown in Table 4 was continuously injected at the rate of $2 \mathrm{cc} / \mathrm{sec}$ until initial water saturation (Swi) was achieved. The displacement of oil was achieved by continuous injection of seawater at the rate of $2 \mathrm{cc} / \mathrm{s}$ until saturation of residual oil $\left(\mathrm{S}_{\text {orw }}\right)$ was achieved and oil recovery during seawater flooding was recorded. After establishing the saturation of residual oil $\left(\mathrm{S}_{\text {orw }}\right)$, achieved by flooding with seawater, two sets of low-salinity flooding were carried out. The first was low-salinity wa- 
terflood (LS1), derived by the dilution of seawater four times while the second low-salinity waterflood (LS2) derived by ten times diluting the seawater. After this, the low salinity brines had ethoxylated alcohol surfactant added to it. Thereafter, another two floods were carried out on each core sample. The first was combined LS1 and surfactant flood designated as LSS1 while the second was combined LS2 and surfactant flood designated as LSS2. At this point, LSS1 was continuously injected at a constant rate of 2 cubic centimetre per second until water cuts obtained were high and also stable. The low injection rate of $2 \mathrm{cc} / \mathrm{sec}$ was used to avoid: 1) any form of damage to the rock sample 2) change of water saturation of the core sample when the measurements were in process 3) entrainment of fine particle and mobilization. The properties of ethoxylated alcohol surfactant solution were significantly improved in the presence infinitesimal amounts of divalent cations, which is a motivation that necessitated the choice of larger amounts of sodium chloride in the formulation of low saline brine solution. The coreflooding were performed at ambient temperature and pressure. The injection fluids Properties are shown in Table 1, Table 2, Table 5 and Table 6 with Figure 1 showing the schematic for the coreflood experimental setup.

\subsection{Measurements of Dispersion}

To have indebt knowledge of fluid flow in the reservoir core sample, dispersions were measured at Sor and at Swi of $100 \%$. Profiles of dispersion for the utilized rock samples at Sor and at Swi of 100\% were carried out after cleaning the rock

Table 3. Properties of the Niger delta rock.

\begin{tabular}{crrrrrr}
\hline Sample No. Length (cm) & $\begin{array}{r}\text { Diameter } \\
(\mathrm{cm})\end{array}$ & $\begin{array}{r}\text { Air Perm } \\
(\mathrm{md})\end{array}$ & $\begin{array}{r}\text { Brine Perm } \\
(\mathrm{md})\end{array}$ & Porosity & PV \\
\hline 1 & 6.35 & 3.81 & 2146 & 1050 & 0.2568 & 64.56 \\
2 & 6.35 & 3.81 & 2157 & 1055 & 0.2561 & \\
3 & 6.35 & 3.81 & 1994 & 993 & 0.2469 & \\
4 & 6.35 & 3.81 & 2132 & 1017 & 0.2434 \\
\hline
\end{tabular}

Table 4. Properties BUK1 Reservoir crude oil.

\begin{tabular}{rrrrr}
\hline Crude Oil ID & $\rho 25^{\circ} \mathrm{C}\left(\mathrm{g} / \mathrm{cm}^{3}\right)$ & $\mu 25^{\circ} \mathrm{C}(\mathrm{cp})$ & AN (mg KOH/g oil) & BN (mg KOH/g oil) \\
\hline BUK 1 & 0.8784 & 6.1413 & $2.48 \pm 0.01$ & $0.86 \pm 0.10$ \\
\hline
\end{tabular}

Table 5. Niger delta formation water ionic composition.

\begin{tabular}{rr}
\hline Ion & Composition \\
\hline $\mathrm{Na}$ & 4600 \\
$\mathrm{~K}$ & 601 \\
$\mathrm{Mg}$ & 145 \\
$\mathrm{Cl}$ & 8820 \\
$\mathrm{TDS}$ & 14,166 \\
\hline
\end{tabular}


Table 6. Other properties of injection fluid ( $\mathrm{pH}$ measurements as well as IFT).

\begin{tabular}{rrrr}
\hline Fluid & $\mu(\mathrm{cp})$ & $\begin{array}{r}\text { IFT (between BUK } 1 \text { crude } \\
\text { oil and brine) dyne/cm }\end{array}$ & $\mathrm{pH}$ \\
\hline SW & 0.934 & 18.680 & 7.614 \\
LS1 & 1.046 & 21.120 & 7.138 \\
LS2 & 1.103 & 22.780 & 6.829 \\
LS1 + Surfactant & 1.803 & 4.416 & 7.980 \\
\hline
\end{tabular}

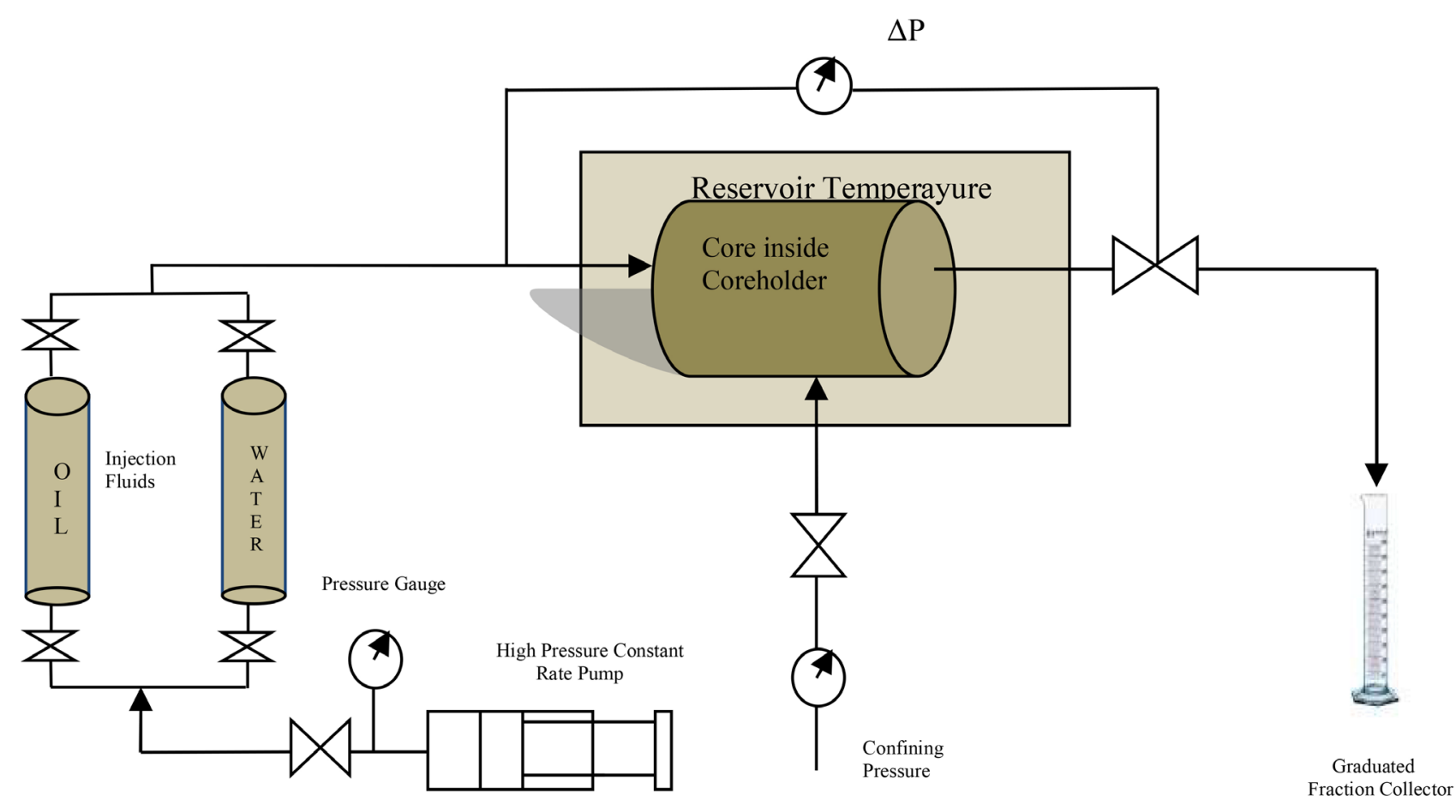

Figure 1. Schematic for the coreflood experimental setup.

samples with methanol and toluene and were gotten by measurement of the effluent resistance for the different salinity utilized for the core flood experiment outside the connate brine.

This is a two phase core flood setup. The coreholder had core samples put inside it and pressure of 1000 psi confined with temperature of reservoir maintained at $100^{\circ} \mathrm{F}$ to get the condition of the reservoir mimicked. When seawater or low saline brine was flooded, the fluids produced are being collected via the graduated fraction collector. When oil is flooded, another graduated fraction collector was put in place to collect the fluids produced which was centrifuged and then measured. The flooding was done with constant rate pump, the pressure gauges were used to obtain the pressures at designated points and the valves employed to control fluid flow

\section{Results and Discussion}

\subsection{Measurement of IFT}

Investigation of the brine salinity effect on the brine-oil interfacial tension was 
carried with the Fisher Scientific Tensiometer Model 20 at ambient conditions. As shown in Table 1, Table 2, Table 6, the brine-oil IFT values increases as the salinity decreases whereas there is a tremendous reduction in the IFT values in the case of surfactant. Alameri et al., 2014; Teklu et al., 2016, [28] [36], posited that a reduction in IFT as seen in Surfactant cannot be the mechanism through which additional increment in oil recovery can be gotten by flooding with low saline brine. Again, as shown in the Table 1, Table 2, Table 6 and Figure 2, there was a tremendous reduction in the IFT values of LSS. This shows that the effect of reduction in brine salinity can positively impact on the brine-oil interfacial tension.

\subsection{LS and LSS Injections}

Figure 3 depicts the data of displacement experiments conducted in four rock samples grouped into two. The figure shows variations in the oil recoveries which were obtained from low salinity core floods. The injection of seawater continuously into the rock sample started from the initial water saturation. The group A rock samples which were not fired had lower recoveries of $24.1 \%$ OOIP for sample 1 with permeability of $1050 \mathrm{md}$ and $21.1 \%$ OOIP for sample 2 with permeability of 1055 md while the group B samples which were fired, even though they had lower permeabilities of 993 md for sample 3 and 1017 md for

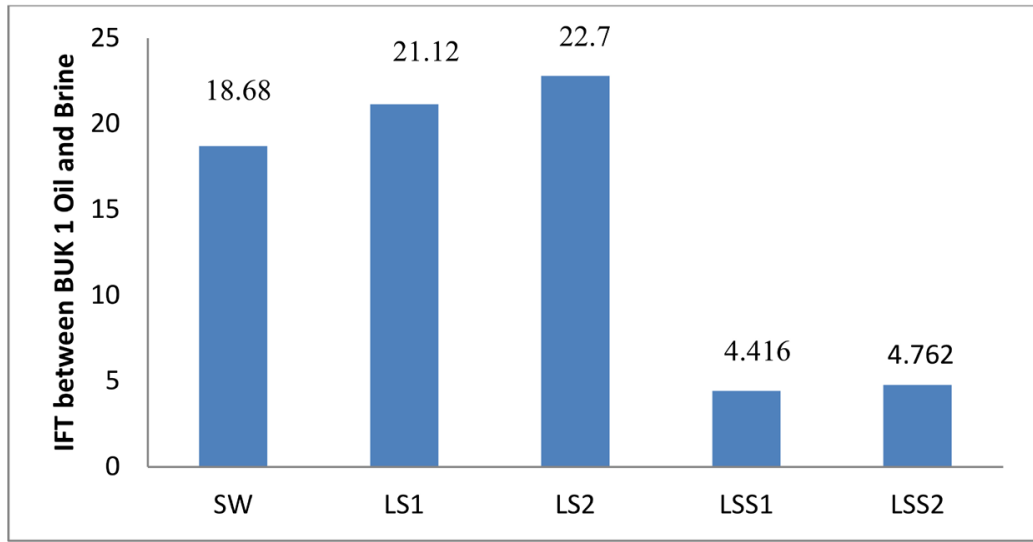

Figure 2. Measured IFT values between BUK 1 crude oil and various injection fluids.

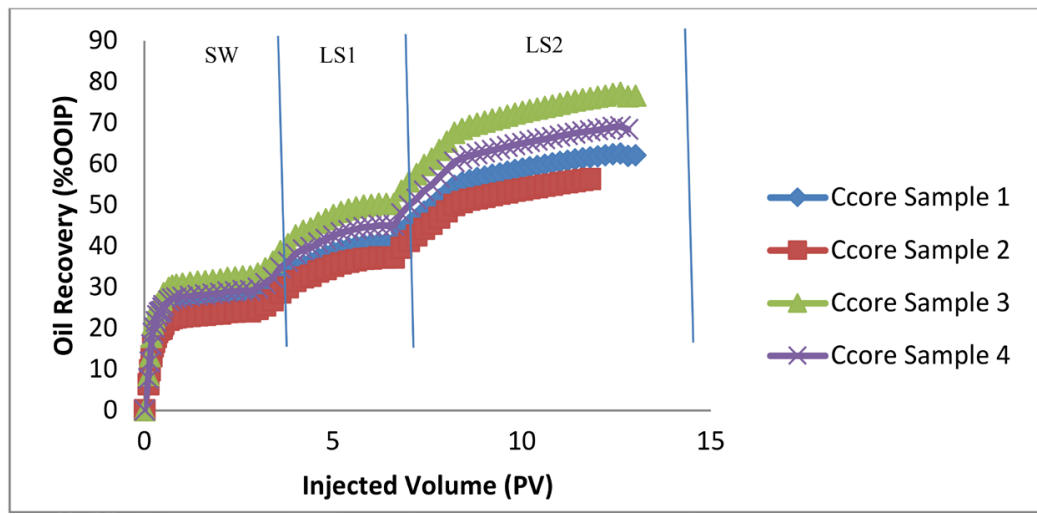

Figure 3. Oil recoveries from rock samples 1 to 4 by injected Seawater (SW), LS1 and LSS1. 
sample 4, higher recoveries were obtained with 29.7\% OOIP for sample 3 and $25.5 \%$ OOIP for sample 4 . These recoveries were achieved before water breakthrough and further seawater injection into the cores gave a slow and gradual increase in oil recovery totaling $26.4 \%$ OOIP for sample 1 with permeability of $1050 \mathrm{md}$ and $24.1 \%$ OOIP for sample 2 with permeability of $1055 \mathrm{md}$ while the group B samples which were fired had 32.6\% OOIP for sample 3 and $29.1 \%$ OOIP for sample 4 . A reduction in the ionic concentrations that occurred when the seawater was four times diluted (LS1) gave an increment in recovery of $14.3 \%$ for sample $1,13.3 \%$ for sample $2,17.7 \%$ for sample 3 and $15.9 \%$ for sample 4 . Then with continuous injection of LS1 combined with surfactant designated as LSS1, an increment in oil recovery of $21.7 \%$ OOIP was gotten for sample $1,19.5 \%$ for sample 2, 26.9\% for sample 3 while sample 4 gave a recovery of $23.4 \%$ as also shown in Figure 3. When LS2 was continuously injected after the seawater flooding, an additional oil recovery of $9.8 \%$ was obtained for sample 1 , $7.1 \%$ for sample 2, $12.6 \%$ for sample 3 and $10.7 \%$ was recovered for sample 4 . Thereafter, with continuous injection of LS1 combined with surfactant designated as LSS2, an increment in recovery of $15.4 \%$ was gotten for sample $1,13.5 \%$ for sample 2, 19.7\% for sample 3 and $16.9 \%$ for sample 4 as shown in Figure 4. From the results, LS1 gave higher recoveries when compared with LS2 while LSS1 gave higher recoveries when compared with LSS2. In all the cases tested, core samples with lower permeabilities which were fired gave higher recoveries than those with higher permeabilties which were not fired, with sample 3 with permeability of $993 \mathrm{md}$ having the highest recoveries in all tested cases. Contrarily, Jin et al., 2016 [37] stated that permeability increase causes proportional oil recovery increment. The result of the fired cores was attributed to the alteration of wettability as well as that of permeability caused by sample firing. The results has proved that firing/no-firing of rock samples before flooding sequences gave rise to various core sensitivities to low salinity brine injection/surfactant flooding. From the results, fluids with low IFT had higher recoveries. This is an indication that reduction of the IFT of the brine/brine + surfactant-oil-reservoir rock system increases the recovery of oil from a water-wet rock. Elmofty, 2012 [38],

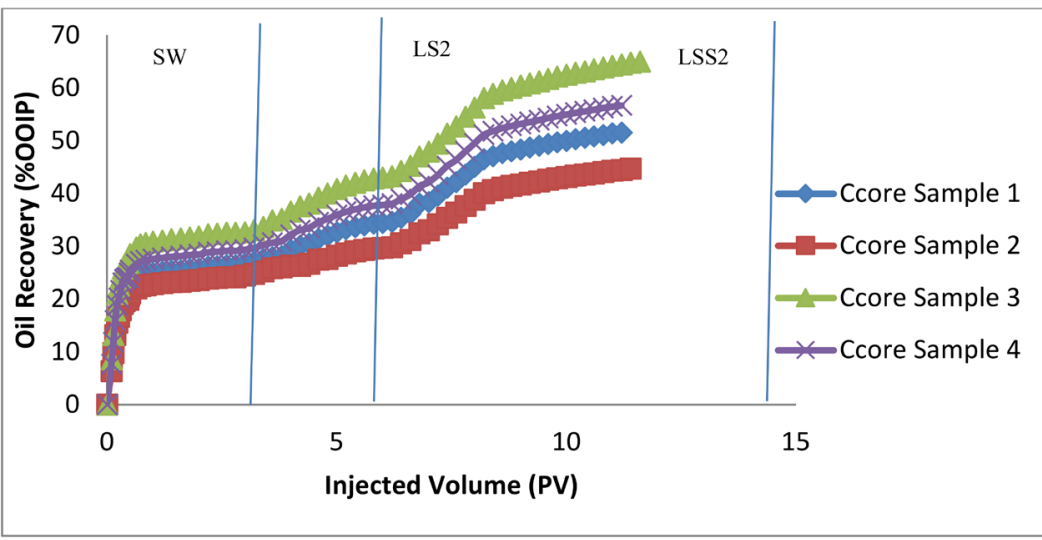

Figure 4. Oil recoveries from rock samples 1 to 4 by injected Seawater (SW), LS2 and LSS2. 
pointed out that apart from wettability alteration effect on the recovery of oil, achieving ultra-low IFT will result in increased recovery of oil through the elimination of unfavorable effect of the oil been retained in the capillaries.

\subsection{Dispersion}

The dispersion profiles for the rock samples 1 - 4 are as depicted in Figure 5 and Figure 6. The four rock samples are all homogeneous as can be noticed in Figure 5, close to ideal dispersion was displayed, with half of the volume injected breaking through after $1 \mathrm{PV}$ and the figure shows that the profile was closely symmetrical. From Figure 5, there was no early breakthrough as such majority of the pores participated in the fluid flow. This means the effective pore volume during fluid flow is approximately equal to the total pore volume. From Figure 6 , after the core samples have been cleaned at water saturation of $100 \%$, the profile shifted towards the right, indicating a dispersion profile that is more symmetrical and ideal in behaviour. The shift to the right was because residual oil was blocking few pores, and this gave rise to few isolated as well as few dead-end pores. When the core samples were then cleaned, the few pores that were previously isolated and few dead-ends became very accessible and thus contributed to fluid flow thereby displaying a dispersion profile that is more ideal.

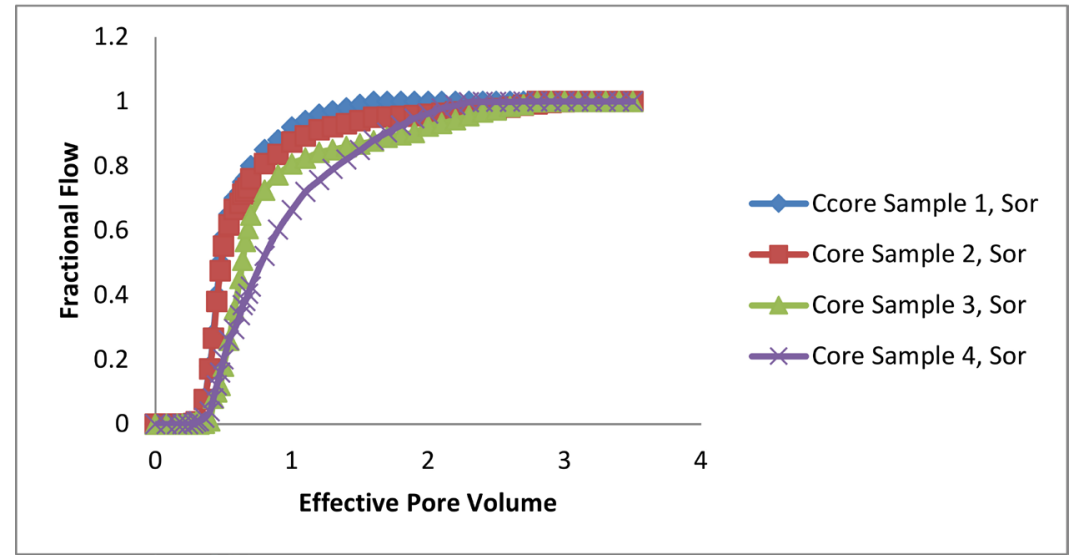

Figure 5. Profile of dispersion for core samples 1 - 4 at Sor.

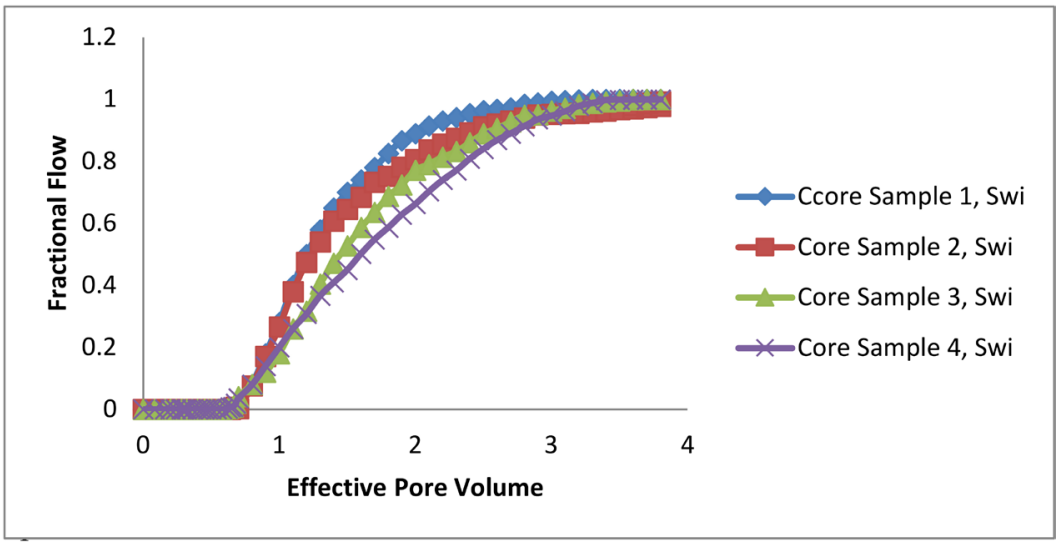

Figure 6. Profile of dispersion for core samples 1 - 4 at Swi. 


\section{Conclusions}

From the research carried out, the following conclusions are drawn based on the results:

- Core samples which were fired gave higher recoveries than those which were not fired in all the cases tested. This has proved that firing/no-firing of rock samples before flooding sequences gave rise to various sensitivities exhibited by the core to low salinity brine injection/surfactant flooding.

- The first low salinity brine gotten when the seawater was 4 times diluted (LS1) gave higher recoveries than the low salinity brine obtained by diluting the seawater ten times (LS2).

- The increment in oil recovery gotten by the injection of a combination of LS2 and surfactant designated as LSS2 was higher than that obtained by the injection of a combination of LS1 and surfactant designated as LSS1.

- The dispersion profiles of the rock samples show that all samples are homogeneous. Thus dispersion measurements help to indicate that a core could be homogeneous or heterogeneous.

\section{Contribution of Study}

The study has proved that core sample firing also causes alteration of wettability as well as that of permeability of the rock thereby leading to increment in oil recovery.

\section{Acknowledgments}

The author acknowledges the support of Kerolycyn Engineering Services Limited for the assistance in providing the samples and certain materials for the experiment and Obmond Energy Nig. Limited for the partial funding of this research as part of community intervention and indigenous capacity building of the Ochia-Assa projects.

\section{Conflicts of Interest}

The author declares no conflicts of interest regarding the publication of this paper.

\section{References}

[1] Anderson, W.G. (1987) Wettability Literature Survey-Part 4: Effects of Wettability on Capillary Pressure. SPE Journal of Petroleum Technology, 39, 1283-1300. https://doi.org/10.2118/15271-PA

[2] AI-Aulaqi, T. (2012) Wettability Alteration in Rock Reservoirs and Its Effect in Petroleum Recovery. Ph.D. Thesis, University of Leeds, Leeds.

[3] Owens, W.W. and Archer, O.L. (1971) The Effect of Rock Wettability on Oil-Water Relative Permeability Relationships. Journal of Petroleum Technology, 23, 873. https://doi.org/10.2118/3034-PA

[4] Morrow, N.R. (1976) Capillary Pressure Correlations for Unifonnly-Wetted Porous Media. Journal of Canadian Petroleum Technology, 15, 49-69. 
https://doi.org/10.2118/76-04-05

[5] Al-Mjeni, R., Arora, S., Cherukupalli, P., Wunnik, J.V., Edwards, J., Felber, B.J., Gurpinar, O., Hirasaki, G., Miller, C., Jackson, C., Kristensen, M., Lim, F. and Ramamoorthy, R. (2011) Has the Time Come for EOR? Oilfield Review Winter, 22, 16.

[6] Cuiec, L., Bourbiaux, B. and Kalaydjian, F. (1994) Oil Recovery by Imbibition in Low-Permeability Chalk. SPE formation Evaluation, 9, 200-208. https://doi.org/10.2118/20259-PA

[7] Kerunwa, A., Onyekonwu, M.O., Olafuyi, A.O. and Anyadiegwu, C.I.C. (2016) Oil Recovery through Spontaneous Imbibition in Niger Delta Reservoirs. International Journal of Engineering Research and Management, 3, 47-52.

[8] Kakati, A., Kumar, G. and Sangwai, J.S. (2020) Oil Recovery Efficiency and Mechanism of Low-Salinity EOR for Light Crude Oil with a Low Acid Number. ACS Omega Publications, 5, 1506-1518. https://doi.org/10.1021/acsomega.9b03229

[9] Austad, T. (2013) Water-based EOR in Sandstones and Carbonates. In: Sheng, J.J., Ed., EOR Field Case Studies, Chapter 13, Elsevier, Waltham, MA, 301-335. https://doi.org/10.1016/B978-0-12-386545-8.00013-0

[10] Tang, G.Q. and Morrow, N.R. (1999) Influence of Fines Migration and Brine Composition on Crude Oil/Brine/Rock Interaction and Oil Recovery. Journal of Petroleum Science and Engineering, 24, 99-111. https://doi.org/10.1016/S0920-4105(99)00034-0

[11] Jadhunandan, P.P. and Morrow, N.R. (1995) Wettability Effect on Waterflood Recovery for Crude Oil/Brine/Rock Systems. SPE Reservoir Engineering, 10, 40-46. https://doi.org/10.2118/22597-PA

[12] Morrow, N.R., Tang, G.Q., Valat, M. and Xie, X. (1998) Improved Oil Recovery Prospects Related to Wettability and Brine Composition. Journal of Petroleum Science and Engineering, 20, 267-276. https://doi.org/10.1016/S0920-4105(98)00030-8

[13] Tang, G.Q. and Morrow, N.R. (1997) Oil Composition, Temperature, Salinity, and Oil Recovery by Waterflooding. SPE Reservoir Engineering, 12, 269-276. https://doi.org/10.2118/36680-PA

[14] Reiter, P.K. (1961) A Water-Sensitive Sandstone Flood Using Low-Salinity Water. Ph.D. Thesis, University of Oklahoma, Norman, OK.

[15] Derkani, M.H., Fletcher, A.J., Abdallah, W., Sauerer, B., Anderson, J. and Zhang, Z.J. (2018) Low-Salinity Waterflooding in Carbonate Reservoirs: Review of Interfacial Mechanisms. Colloids Interfaces, 2, 1-43. https://doi.org/10.3390/colloids2020020

[16] Al-Saedi, H.N. and Flori, R.E. (2018) EOR of Low-Salinity Waterflooding in Sandstone and the Role of Clay. Petroleum Exploration and Development, 45, 927-931. https://doi.org/10.1016/S1876-3804(18)30096-X

[17] Lager, A., Webb, K.J. and Black, C.J.J. (2008) Low-Salinity Oil Recovery: Experimental Investigation. Petrophysics, 49, 28-35.

[18] Aksulu, H., Hå Msø, D., Strand, S., et al. (2012) Evaluation of Low Saline EOR Effects in Sandstone: Temperature and $\mathrm{pH}$ Gradient Effects. Energy Fuels, 26, 3497-3503. https://doi.org/10.1021/ef300162n

[19] Ligthelm, D.J., Gronsveld, J. and Hofman, J.P. (2009) Novel Strategy for Water Flooding by Manipulation of Injection-Brine Composition. Paper No. SPE 119835. https://doi.org/10.2118/119835-MS 
[20] Mcguire, P.L., Chatham, J.R. and Paskvan, F.K. (2005) Low-Salinity Oil Recovery: Exciting New EOR Opportunity for Alaska's North Slope. Paper No. SPE 93903-MS. https://doi.org/10.2118/93903-MS

[21] Austad, T., Rezaeidoust, A. and Puntervold, T. (2010) Chemical Mechanism of Low-Salinity Waterflooding in Sandstone Reservoirs. Paper No. SPE 129767. https://doi.org/10.2118/129767-MS

[22] Rezaeidoust, A., Puntervold, T. and Strand, S. (2009) Smart-Water as Wettability Modifier in Carbonate and Sandstone: A Discussion of Similarities/Differences in the Chemical Mechanisms. Energy Fuels, 23, 4479-4485. https://doi.org/10.1021/ef900185q

[23] Rezaeidoust, A., Puntervold, T. and Austad, T. (2011) Chemical Verification of Mechanism of EOR by Using Low Saline/Smart-Water in Sandstone. Energy Fuels, 25, 151-2162. https://doi.org/10.1021/ef200215y

[24] Zhang, P., Tweheyo, M.T. and Austad, T. (2007) Alteration of Wettability and Oil Recovery Improvement by Seawater Imbibition into Chalk. Colloids and Surfaces A, 301, 199-208. https://doi.org/10.1016/j.colsurfa.2006.12.058

[25] Barber, L.B., Thurman, E. and Runnells, D.D. (1992) Geochemical Heterogeneity in Gravel and Sand Aquifer: Effect of Particle Size and Mineralogy of Sediment and on Chlorobenzenes Sorption. Journal of Contaminant Hydrology, 9, 35-54. https://doi.org/10.1016/0169-7722(92)90049-K

[26] Heidari, P. and Li, L. (2014) Transport of Solute in Sand Boxes with Low-Heterogeneity: The Role of Permeability Variance and Correlation Length. Water Resources Research, 50, 8240-8264. https://doi.org/10.1002/2013WR014654

[27] Salehikhoo, F., Li, L. and Brantley, S.L. (2013) Magnesite Dissolution Rates at Varying Spatial Scales: The Role of Flow Velocity and Mineral Spatial Distribution and Flow Velocity. Geochimica et Cosmochimica Acta, 108, 91-106. https://doi.org/10.1016/j.gca.2013.01.010

[28] Teklu, T.W., Alameri, W., Kazemi, H., Graves, R.M. and AlSumaiti, A.M. (2017) Low-Salinity Water-Surfactant-CO $\mathrm{CO}_{2}$ EOR. Petroleum, 3, 309-320. https://doi.org/10.1016/j.petlm.2017.03.003

[29] Tavassoli, S., Korrani, A.K.N., Pope, G.A. and Sepehrnoori, K. (2015) Low-Salinity Surfactant Flooding-A Multimechanistic EOR Method. Paper No. SPE 173801. https://doi.org/10.2118/173801-MS

[30] Bansal, V.K. and Shah, D.O. (1976) Micellar Solutions for Improved Oil Recovery. In: Mittal, K.L., Ed., Micellization, Solubilization, and Microemulsions, Volume 1, Plenum Press, New York, 87-113. https://doi.org/10.1007/978-1-4684-2346-4_6

[31] Alagic, E., Spildo, K., Skauge, A. and Solbakken, J. (2011) Effect of Crude Oil Ageing on Low-Salinity and Low-Salinity Surfactant Flooding. The Journal of Petroleum Science and Engineering, 78, 220-227. https://doi.org/10.1016/j.petrol.2011.06.021

[32] Lake, L.W. (1989) Enhanced Oil Recovery. Prentice Hall, Upper Saddle River, NJ.

[33] Friedmann, F. (1986) Surfactant and Polymer Losses during Flow through Porous Media. SPE Reservoir Engineering, 1, 261-271. https://doi.org/10.2118/11779-PA

[34] Alagic, E. and Skauge, A. (2010) Combined Low-Salinity Brine-Injection and Surfactant Flooding in Mixed-Wet-Sandstone Cores. Energy Fuels, 24, 3551-3559. https://doi.org/10.1021/ef1000908

[35] Alameri, W., Teklu, T.W., Graves, R.M., Kazemi, H. and Al Sumaiti, A.M. (2015) Low-Salinity Water-Alternating-Surfactant in Low-Permeability Carbonate Reservoirs. 18th European Symposium on IOR Conference, Dresden, Germany, 14-16 
April 2015. https://doi.org/10.3997/2214-4609.201412158

[36] Teklu, T.W., Alameri, W., Kazemi, H., Graves, R.M. and Al Sumaiti, A.M. (2016) Low Salinity Water-Alternating-CO ${ }_{2}$ EOR. Petroleum, 142, 101-118. https://doi.org/10.1016/j.petrol.2016.01.031

[37] Jin, F., Wang, S., Pu, W., Liu, X., Yuan, C., Zhao, S., Tang, Y. and Dou, L. (2016) Effects of IFT, Permeability and Injection Rate on Recovery of Oil in Dilute Surfactant Flooding. Petroleum Science and Technology, 34, 1490-1495. https://doi.org/10.1080/10916466.2016.1208228

[38] Elmofty, O. (2012) Surfactant EOR by Alteration of Wettability in Sandstone Reservoirs. Master's Thesis, Missouri University of Science and Technology, Rolla, MO.

\section{Nomenclature}

EOR_Enhanced oil recovery

IFT-Interfacial tension

LS-Low saline brine

LSS-LS + surfactant

OOIP-Original oil in place

Relperm-Relative permeability 